\title{
A Sensitive and Reproducible Spectrophotometric Assay for Glucose Oxidase Activity and Its Application in Conformational Lock
}

\author{
Fangyong GENG \\ School of Life Sciences \\ Henan University, \\ Kaifeng, China \\ e-mail: 453921130@qq.com \\ Yunfei GAO \\ School of Life Sciences \\ Henan University, \\ Kaifeng, China \\ e-mail: 453921130@qq.com
}

\author{
Di LI \\ School of Life Sciences \\ Henan University, \\ Kaifeng, China \\ e-mail: 453921130@qq.com
}

\author{
Baolin XIAO \\ School of Life Sciences \\ Henan University, \\ Kaifeng, China \\ e-mail:78448742@qq.com
}

\author{
Jun HONG* \\ Institute of Biotechnology and School of Life Sciences \\ Henan University \\ Kaifeng, China \\ e-mail: hongjun@henu.edu.cn \\ Ali Akbar MOOSAVI-MOVAHEDI* \\ Institute of Biochemistry and Biophysics \\ University of Tehran \\ Tehran, Iran \\ e-mail: moosavi@ibb.ut.ac.ir \\ Fang-Yong Geng, Di Li and Yun-Fei Gao contributed equally to this work.
}

\begin{abstract}
Glucose-oxidase-horseradish peroxidaseguaiacol coupled system was applied for glucose oxidase assay with high sensitivity and prefect reproducibility. The optimum $\mathrm{pH}$ value was 5.8. The Michaelis-Menten constant $(\mathrm{Km})$ and $V \max$ were determined to be $30.0 \pm 1.0 \mathrm{mM}$ and $2.49 \pm 0.08 \mu \mathrm{M} / \mathrm{s}$, respectively, for the assay system at $25^{\circ} \mathrm{C}$. The relative standard deviation was $2.8 \%$ for 31 times measurements of GOD activity. The GOD assay could be applied in conformational lock study on GOD. Results of bio-thermodynamics suggested that the number of contact area of GOD is two, which is consistent with the computation results by using Ligplot and Pymol.
\end{abstract}

Keywords-spectrophotometic assay; glucose oxidase; guaiacol; horseradish peroxidase; coupled system; conformational lock

\section{INTRODUCTION}

Glucose oxidase (GOD) is an identical dimer and rigid glycoprotein, which catalyzes glucose in the presence of oxygen to gluconic acid and hydrogen peroxide [1]. The measurement of glucose oxidase activity is the basis study of its performance, with various methods. In a hydrochloric acid titration method [1], $\mathrm{NaOH}$ was added to glucose oxidase and $\beta$-D-glucose reaction system to terminate the reaction process, and then, a certain amount of hydrochloric acid was titrated in the system to calculate the consumption of hydrochloric acid solution, and concluded that the activity of glucose oxidase. In a spectroscopic method [2-3], glucose oxidase catalyzes the $\beta$-D-glucose to hydrogen peroxide. In the presence of peroxidase, the activity of glucose oxidase can be measured by determination of colored product formation rate.

Phenol and o-dianisidine are two common chromogens. Unfortunately, phenol is volatile and harmful to the human body, the solubility of o-dianisidine in aqueous solution is low and the colored product has the maximum absorption peak at $400 \mathrm{~nm}$, which is unstable and easily disturbed by some background material in the sample [4].

The conformational lock is a bio-thermodynamic theory, which was suggested by Poltorak for the first time in 1998, to explain the properties of interfaces in oligomeric enzymes and their influence on catalytic activity through two independent methods, involving the use of the structural and kinetics data. From then on, various dimer enzymes from different sources have been investigated that in both methods are in reasonable agreement. Conformational lock theory may provide a special explanation about the process of thermal dissociation and denaturation of oligomeric proteins [5-10].

In this report, a new spectrophotometic method was proposed for the determination of GOD activity using a guaiacol-horseradish peroxidase-glucose oxidase coupled system. The suggested method has good sensitivity, reproducibility, and measurement accuracy. The GOD assay could be applied successfully in research on the conformational lock of the GOD. 


\section{EXPERIMENTAL}

\section{A. Reagents}

Glucose oxidase from Aspergillus niger (GOD), $\beta$-Dglucose, o-dianisidine dihydrochloride, guaiacol and horseradish peroxidase (HRP, type II) were from Sigma. All chemicals were analytical grade without further purification. Double distilled water was used throughout these studies.

\section{B. The Kinetic Measurements}

The activity of the glucose oxidase was determined using a TU-1901 spectrophotometer equipped with a temperature controller at $25^{\circ} \mathrm{C}$. HRP, GOD and guaiacol were added to phosphate buffer solution (PBS) and the reaction was initiated by adding $\beta$-D-glucose. The initial guaiacol oxidation rate was determined by the rate of colored product (tetraguaiacol, $\varepsilon 470 \mathrm{~nm}=26.6 \mathrm{mM}^{-1} \mathrm{~cm}^{-1}$ ) [11-14]. Then initial rate of the reaction of glucose can be converted and the activity of GOD could be obtained. The relative reaction could be expressed as follows (Eq. 1 and 2):

$$
\text { Glucose }+\mathrm{O}_{2} \stackrel{\text { GOD }}{\longrightarrow} \text { Gluconolactone }+\mathrm{H}_{2} \mathrm{O}_{2}
$$

$$
4 \mathrm{H}_{2} \mathrm{O}_{2}+4 \mathrm{Guaiacol} \stackrel{\mathrm{HRP}}{\longrightarrow} \text { Tetraguaiacol }+8 \mathrm{H}_{2} \mathrm{O}(2)
$$

The activity of GOD was calculated based on Eq. 3:

$$
\text { Units } / \mathrm{mg}=\frac{4 \times \Delta \mathrm{A}_{470 \mathrm{~nm}} / \mathrm{min}}{\varepsilon_{470 \mathrm{~nm}} \times \mathrm{mg}(\text { enzy me }) / \mathrm{ml}(\text { reaction mixture })}
$$

\section{Research on Thermal Dissociation and Optimum Temperature (Topt) of GOD}

The GOD samples (in various vials) were incubated separately at different temperatures in 50mM PBS at pH 5.8 for 30 minutes, then the samples was removed and cooled immediately in an ice-water bath and assayed for residual activity of GOD.

Optimum temperature $\left(\mathrm{T}_{\mathrm{opt}}\right)$ has been defined as the maximum temperature at which the activity of the enzyme does not change during the incubation time [15]. GOD samples at a concentration of were incubated in the thermostat at different temperatures in 50mM PBS at pH 5.8 for a certain minutes, cooled rapidly in an ice-water bath, and assayed for residual activity of GOD. The final concentrations of GOD, glucose, guaiacol and HRP, were $9 \times 10^{-6} \mathrm{mM}, 50 \mathrm{mM}, 3 \mathrm{mM}$, and $2.5 \times 10^{-5} \mathrm{mM}$, respectively.

\section{The Mechanism of Thermal Dissociation and Conformational Lock}

According to the theory of Poltorak, a simple thermal dissociation could be expressed as Eq. 4:

$$
E_{2} \Leftrightarrow 2 E_{1} \Rightarrow 2 E_{d}
$$

$E_{2}$ is an active dimer form of enzyme, $E_{1}$ and $E_{d}$ are the monomers for the reversible transformation of initial structure and for denatured form of irreversible transformation of $\mathrm{E}_{1}$, respectively. The $\mathrm{E}_{\mathrm{d}}$ could not reunite and form an active enzyme $\left(\mathrm{E}_{2}\right)$. Generally, there are several intermediate active forms of dimer enzyme (Eq.5):

$$
E_{2} \Leftrightarrow E_{2}{ }^{1} \Leftrightarrow E_{2}{ }^{2} \Leftrightarrow E_{2}{ }^{3} \ldots E_{2}{ }^{m} \Leftrightarrow 2 E_{1} \Rightarrow 2 E_{d}
$$

It was supposed that the real number $(\mathrm{m})$ of intermediates of catalytically active protein is always greater than a certain quantity (n). Here, $n$ represents different active forms of the dimer enzyme, and can be obtained from an empirical Eq. 6 and 7 [5-10]:

$$
\begin{gathered}
n=\frac{0.13+\delta}{0.13-0.05 \delta} \\
\delta=R-1
\end{gathered}
$$

Where, $\delta$ is obtained from the kinetic plot of residue active versus time and depending only on the number of steps (n) before loss of activity of enzyme. These make it possible to estimate the minimal number of steps for a dimer enzyme in the process of thermal dissociation into inactive monomers. These phenomenons of interprotein contacts with possible partial breaks were also supposed as "conformational lock".

\section{E. Biochemical Computation by Using Ligplot and Pymol}

Ligplot ${ }^{[16]}$ is a computer program for plotting interactions of protein-ligand. This program can generate schematic diagrams automatically of protein-ligand interactions from a given PDB file. The operating manual is located at the site:

http://www.biochem.ucl.ac.uk/bsm/ligplot/manual/.

Pymol is an open source based molecular visualization system initiated by user, and used to view 3D molecular structures of a protein's PDB file.

\section{RESUlTS AND DiscUSSION}

\section{A. Time Dependence of $U V$-Vis Spectra During GOD Assay}

UV-vis spectra of the guaiacol oxidation process were shown in Fig.1. A colored product increased gradually at $470 \mathrm{~nm}$ with increasing time, it is supposed that GOD catalyzes glucose to produce hydrogen peroxide $\left(\mathrm{H}_{2} \mathrm{O}_{2}\right)$ in the presence of oxygen, then guaiacol react with $\mathrm{H}_{2} \mathrm{O}_{2}$ in the presence of HRP, and generates a colored product (tetraguaiacol). At last, the activity of GOD could be converted easily (see also Eqs. 1, 2 and 3). 


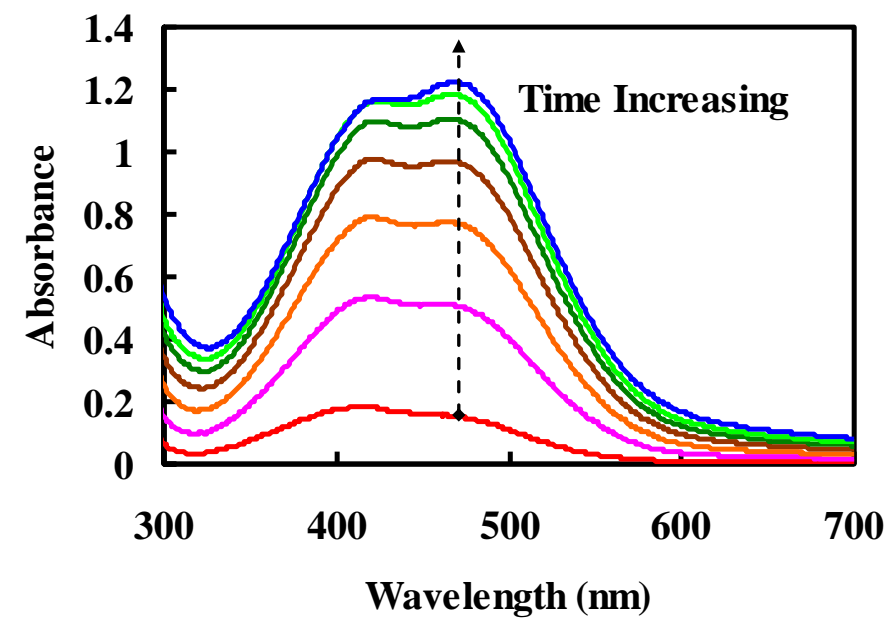

Figure. 1. Time dependence of UV-vis spectra of GOD in the presence of glucose, guaiacol and HRP in 50mM, pH5.8 PBS

The spectra were collected at 100 s intervals.

\section{B. The Sensitivity Comparison between Guaiacol and $O$ - Dianisidine Methods in GOD Assay}

The guaiacol and o-dianisidine in the presence of HRP, GOD and glucose were used as chromogens for GOD assay. It could be seen that the guaiacol shows a higher sensitivity (Fig.2A and B, curve a) respect to o-dianisidine (Fig.2A and B, curve b). The Fig.2B was generated from Fig.2A. It could be seen that the two methods have very good linearity in the beginning of enzymatic reaction. The o-dianisidine method was suggested by sigma .

(http://www.sigmaaldrich.com/china-mainland/zh/technicaldocuments/protocols/biology/enzymatic-assay-of-glucoseoxidase.html).
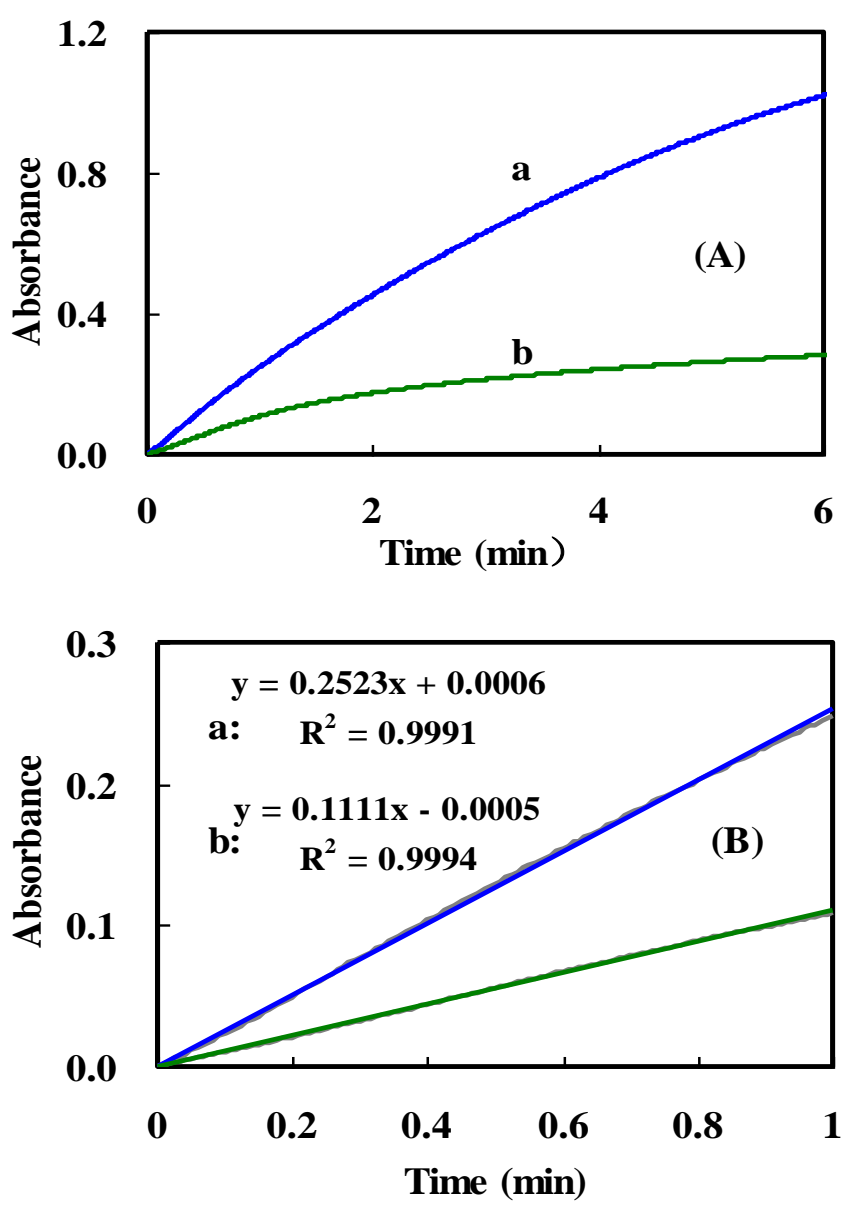

Figure. 2. (A) Relationship between absorbance and time for guaiacol (curve a) and o-dianisidine (curve b) in GOD assay. (B) Sensitivity comparison between guaiacol (curve a) and dianisidine (curve b) methods The experiments were operated at $470 \mathrm{~nm}$ for $3 \mathrm{mM}$ guaiacol (curve a), and $400 \mathrm{~nm}$ for $0.16 \mathrm{mM}$ dianisidine (curve b) in $50 \mathrm{mM}$, pH5.8 PBS at $25^{\circ} \mathrm{C}$ containing $2.5 \times 10^{-5} \mathrm{mM}$ HRP, $9 \times 10^{-6} \mathrm{mM}$ GOD and $50 \mathrm{mM}$ glucose, respectively

\section{Kinetic Parameters of GOD}

The Michaelis-Menten plot and relative LineweaverBurk plot of GOD are represented in Fig.4A and B, respectively. The Michaelis-Menten constant $\left(\mathrm{K}_{\mathrm{m}}\right)$ and maximum reaction rate of glucose $\left(\mathrm{V}_{\max }\right)$ could be obtained from Lineweaver-Burk plot using Eq.8:

$$
\frac{1}{\mathrm{~V}_{0}}=\frac{\mathrm{K}_{\mathrm{m}}}{\mathrm{V}_{\max }[\mathrm{S}]}+\frac{1}{\mathrm{~V}_{\max }}
$$

Where, $\mathrm{V}_{0}$ represents the initial glucose reaction rate in GOD assay. From the regression equation (Fig.3B): $\mathrm{y}=12.03 \mathrm{x}+0.4011$, Vmax and $\mathrm{Km}$ were calculated to be 2.49 $\pm 0.08 \mu \mathrm{M} / \mathrm{s}$ and $30.0 \pm 1.0 \mathrm{mM}$, respectively. The $K_{m}$ value is smaller than data provided by Sigma [16-17]. 

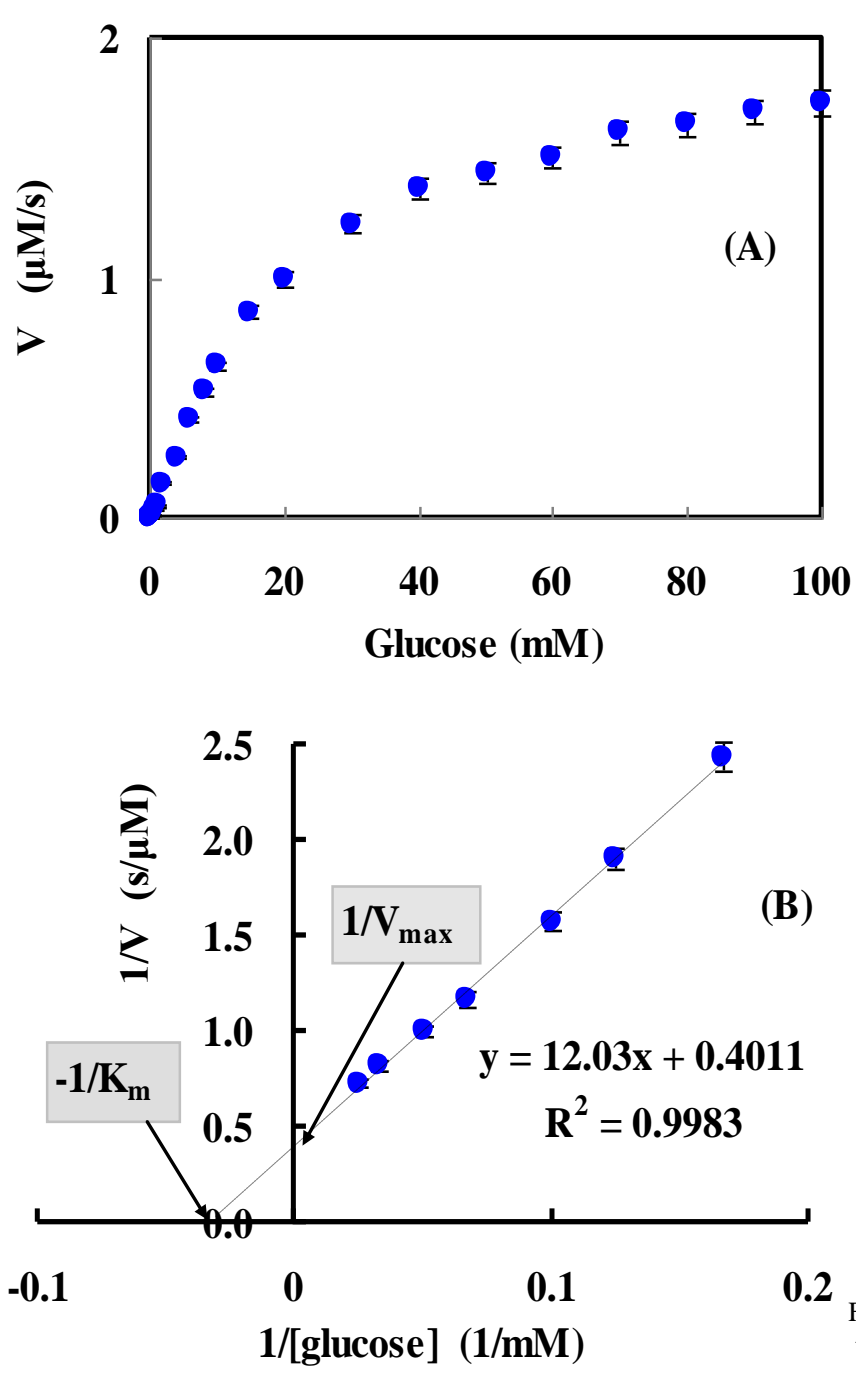

Figure. 3. (A) Michaelis-Menten and (B) Lineweaver-Burk plots of GOD in PBS $\left(50 \mathrm{mM}, \mathrm{pH} 5.8,25^{\circ} \mathrm{C}\right)$ containing HRP $\left(2.5 \times 10^{-5} \mathrm{mM}\right)$, GOD $\left(9 \times 10^{-}\right.$

${ }^{6} \mathrm{mM}$ ), guaiacol ( $3 \mathrm{mM}$ ), and glucose (ranging from 0.05 to $100 \mathrm{mM}$ ).

\section{The Ph Effects and Repeatability of GOD Assay}

Fig.4A represents the effects of $\mathrm{pH}$ values on the GOD activity in the presence of glucose, guaiacol and HRP. The GOD activity increased with increasing $\mathrm{pH}$ value, and reached a maximum value at $\mathrm{pH} 5.8$, which is close to the optimum $\mathrm{pH}$ value (pH5.5) for the native GOD from Aspergillus niger [18-19], indicates that the present GOD assay method does not change the optimum $\mathrm{pH}$ value of GOD.

0.2
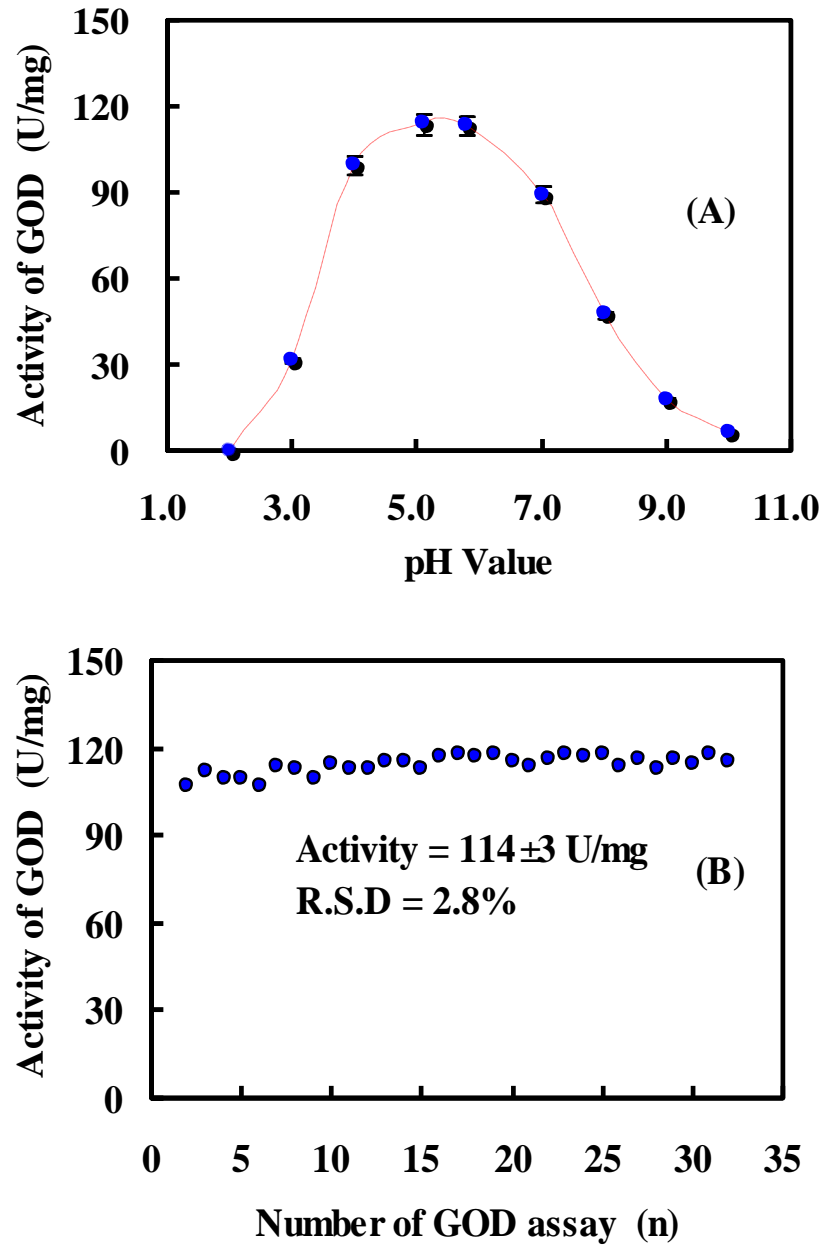

Figure.4 (A) Effects of $\mathrm{pH}$ values on the activity of GOD in 50mM PBS in the presence of GOD $\left(9 \times 10^{-6} \mathrm{mM}\right)$, glucose $(50 \mathrm{mM})$, guaiacol $(3 \mathrm{mM})$ and HRP $\left(2.5 \times 10^{-5} \mathrm{mM}\right)$. (B) Repeatability of the assay of GOD, the experiments was operated in PBS $\left(50 \mathrm{mM}, \mathrm{pH} 5.8,25^{\circ} \mathrm{C}\right)$ containing HRP $\left(2.5 \times 10^{-5} \mathrm{mM}\right)$, GOD $\left(9 \times 10^{-6} \mathrm{mM}\right)$, guaiacol $(3 \mathrm{mM})$, and glucose $(50 \mathrm{mM})$ at $470 \mathrm{~nm}$.

The repeatability of the assay was checked by determining the activity of GOD sample repeatly, and the mean value of the GOD activity was calculated to be $114 \pm$ 3U/mg using Eq.3 (see also Fig.4B), with a relative standard deviation (R.S.D) of $2.8 \%$ for 31 measurements. The determination GOD activity value is consistent with the data provided by sigma (Type VII from Aspergillus niger, Activity $\geq 100 \mathrm{U} / \mathrm{mg}$ ), indicates prefect repeatability of this method.

\section{E. Linear Range and Detection Limit}

To evaluate the linear range and detection limit for the concentration of GOD in this method, reaction rate $(\Delta \mathrm{A} / \mathrm{min})$ of the enzymatic samples was measured when the concentration of GOD was increased gradually. It could be seen that the linear range for measurement of GOD activity was from $4.3 \times 10^{-5} \mathrm{mM}$ to $9.3 \times 10^{-3} \mathrm{mM}$ (Fig.5A). The detection limit was $4.3 \times 10^{-5} \mathrm{mM}$ (Fig.5B) [20-22]. 

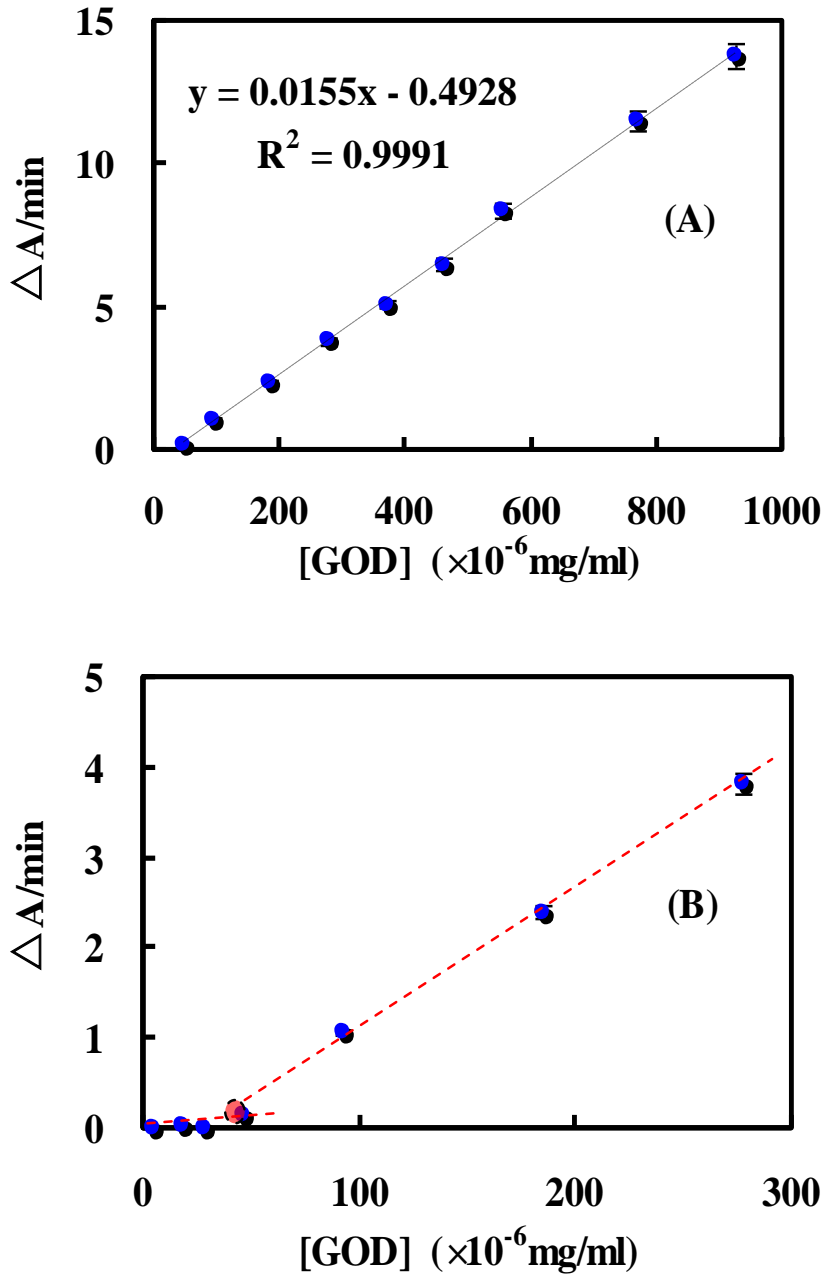

Figure.5 (A) Linear range and (B) Detection limit of the measurement for activity of GOD.

\section{F. Optimum Temperature and N Value of GOD}

There was less change for the residual activity of GOD at incubation temperatures below $55^{\circ} \mathrm{C}$. The activity of GOD will reduce rapidly at above $60^{\circ} \mathrm{C}$. Then, Topt of GOD could be obtained to be $57{ }^{\circ} \mathrm{C}$ (Fig.6A). From Fig.6B, R value could be obtained to be 1.09 and 1.13 , at 60 and $65^{\circ} \mathrm{C}$, respectively. Then $\delta$ value ( $\delta=\mathrm{R}-1)$ could be conclude to be 0.09 and 0.13 , and $\mathrm{n}$ could be calculated to be $1.77(\approx 2)$ and $2.1(\approx 2)$, at 60 and $65^{\circ} \mathrm{C}$, respectively. From the results of the bio-thermodynamic research, there are two contact areas for the dimer GOD.
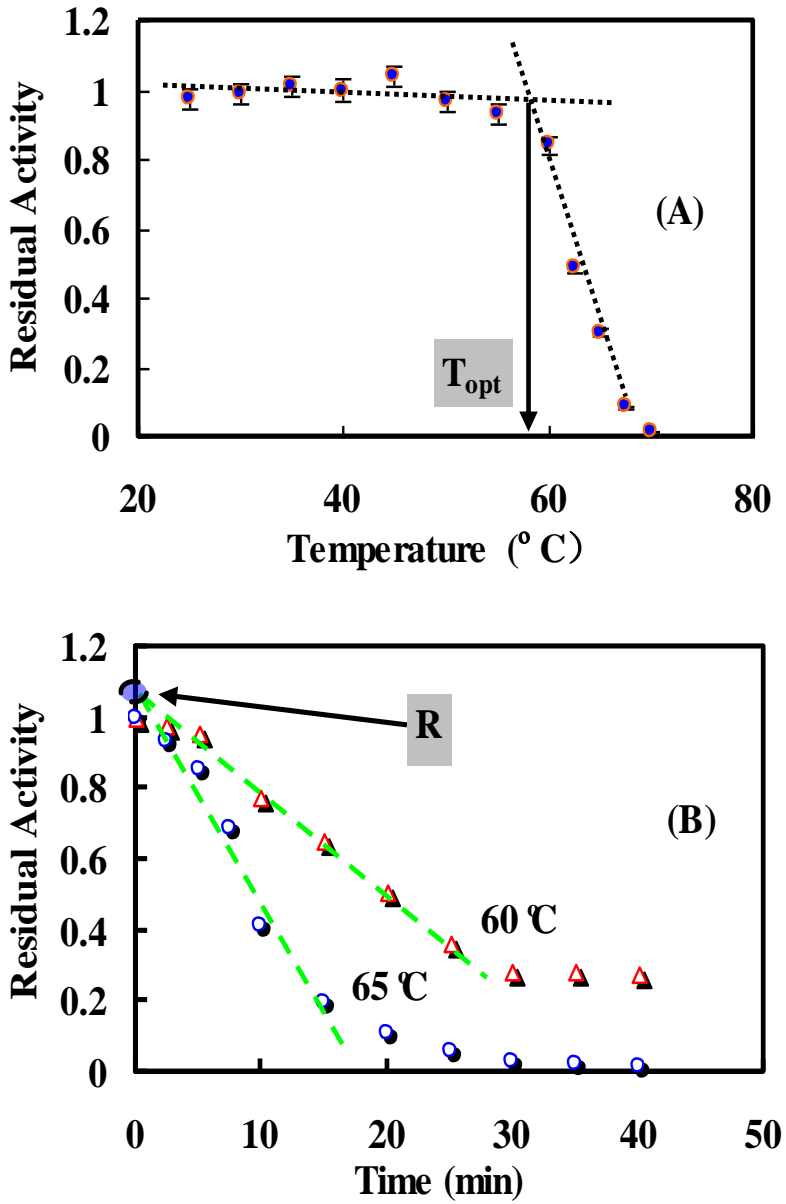

Figure.6 (A) Residual activity of GOD versus incubation temperature in $50 \mathrm{mM}$ PBS in the presence of guaiacol $(3 \mathrm{mM}), \mathrm{HRP}\left(2.5 \times 10^{-5} \mathrm{mM}\right), \mathrm{GOD}$ $\left(9 \times 10^{-6} \mathrm{mM}\right)$ and glucose $(50 \mathrm{mM})$. GOD was incubated at the indicated temperature for $30 \mathrm{~min}$ followed by immediately cooling to $0^{\circ} \mathrm{C}$ in an icewater bath and assayed for residual activity. (B) Thermal dissociation of GOD. The GOD was incubated for a certain time at $60(\Delta)$ and $65^{\circ} \mathrm{C}(\circ)$, respectively, in PBS $(50 \mathrm{mM}, \mathrm{pH} 5.8)$ containing $\mathrm{HRP}\left(2.5 \times 10^{-5} \mathrm{mM}\right)$, GOD $\left(9 \times 10^{-6} \mathrm{mM}\right)$, guaiacol $(3 \mathrm{mM})$, and glucose $(50 \mathrm{mM})$, and quenched in the ice-water bath, and assayed for residual activity.

\section{G. Biochemical Computation of The Conformational Lock of $G O D$}

Fig. 7A and B are generated by using Pymol and Ligplot [16], respectively, to show the contact areas and main interactions involving the contact area. It could be seen that there are two identical contact areas between two subunits of GOD, The amino acid residues (e.g. Asn62, Asp63, Thr80, Lys 277, Leu449 and Tyr448), which are located at each contact area (Fig.7A), may play an important role in conformational lock of GOD. 

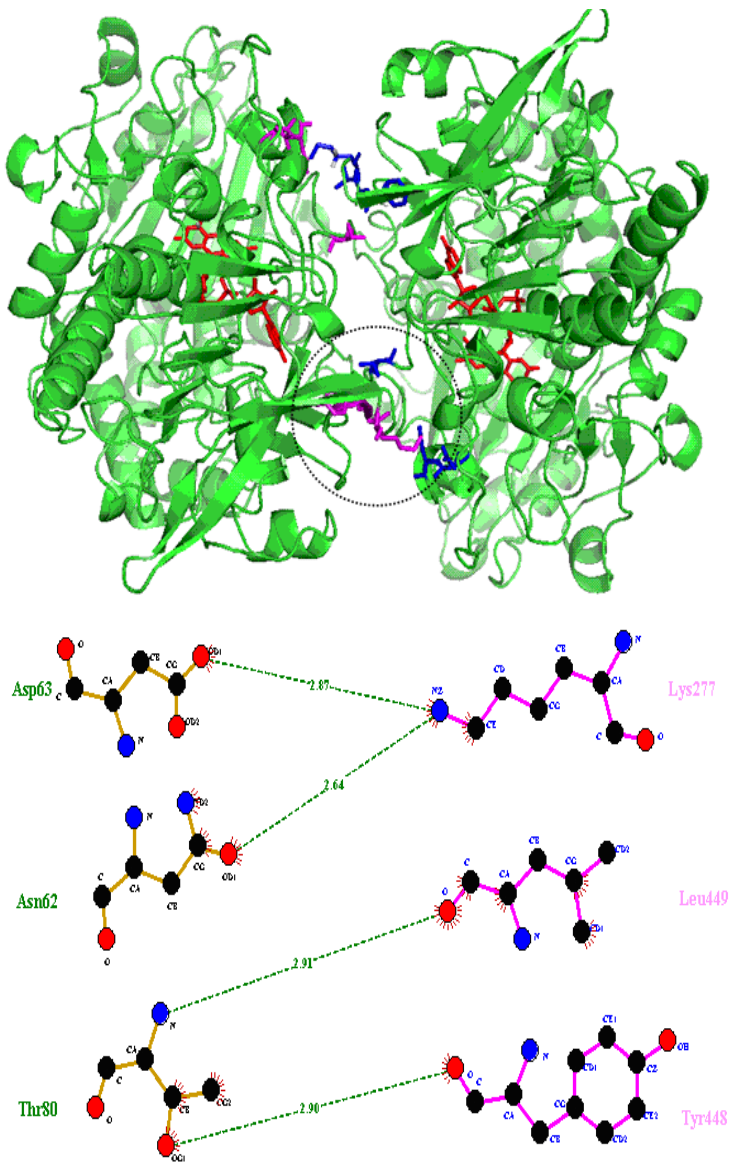

Figure.7 (A) Contact areas of glucose oxidase from Aspergillus niger (PDB ID: 1GPE). The figure was generated by using the Pymol. (B) Amino acids and interactions involving the contact area. The figure was generated by using Liglot. Green dashed lines represent hydrogen bonds, spiked residues show hydrophobic contacts.

\section{CONCLUSIONS}

Glucose oxidase-horseradish peroxidase-guaiacol coupled system could be applied for glucose oxidase assay. The method has prefect repeatability and high sensitivity. The assay could be used for kinetic research about the conformation lock of glucose oxidase.

\section{ACKNOWLEDGMENT}

The support of Development Projects of Henan Province Science and Technology (142300410124), Henan University Science Foundation (Y1425013), the Research Council of University of Tehran and Iran National Science Foundation (INSF) are gratefully acknowledged.

\section{REFERENCES}

[1] T. B. Lu, X.Y. Peng, H.Y. Yang, and L.N. Ji, "The production of glucose oxidase using the waste myceliums of Aspergillus niger and the effects of metal ions on the activity of glucose oxidase," Enzyme and Microbial Technology, vol. 19, pp. 339-342, October 1996.

[2] S. Witt, M. Singh, and H. Kalisz, "Structural and kinetic properties of nonglycosylated recombinant Penicillium amagasakiense glucose oxidase expressed in Escherichia coli," Applied and Environmental Microbiology, vol. 64, pp.1405-1411, April 1998.

[3] Y. Tatsu and S. T. Yamamura, "Fluorescence measurement of glucose bypyrene modified oxidase," Journal of Molecular Catalysis B: Enzymatic, vol. 17, pp . 203-206, June 2002.

[4] H.U. Bergmeyer, K.Gawehn, and M.Grassl, "Methods of Enzymatic Analysis," H.U. Bergmeyer, ed., Academic Press, Inc., New York, , pp. $457-458,1974$.

[5] O.M. Poltorak, E.S. Chukhray, and I.Y. Torshin, Dissociative thermal inactivation, stability and activity of oligomeric enzymes. Biochemistry vol. 63, pp. 303-311, 1998.

[6] O.M. Poltorak, E.S. Chukhray, A. Kozlenkov, M.F. Chaplin, and M.D. Trevan, "The putative common mechanism for inactivation of alkaline phosphatase isoenzymes," Journal of Molecular Catalysis B: Enzymatic, vol. 7, pp. 157-163, September 1999.

[7] O.M. Poltorak, E.S. Chukhray, I.Y. Torshin, L.F. Atyaksheva, M.D. Trevan, and M.F. Chaplin, "Catalytic properties, stability and the structure of the conformational lock in the alkaline phosphatase from Escherichia coli," Journal of Molecular Catalysis B: Enzymatic, vol. 7, pp.165-172, September 1999.

[8] M. Amani, A.A. Moosavi-Movahedi, G. Floris, S. Longu, A. Mura, S.Z. Moosavi-Nejad, A.A. Saboury, and F. "Ahmad Comparative study of conformational lock, dissociative thermal inactivation and stability of Euphorbia latex and lentil seedling amine oxidase," Protein Journal, vol. 24, pp. 183-191, April 2005.

[9] J. Hong, A.A. Moosavi-Movahedi, H. Ghourchian, M. Amani, M. Amanlou, and F.C. Chilaka, "Thermal dissociation and conformational lock of superoxide dismutase." Journal of Biochemistry and Molecular Biology, 38, pp. 533-538, 2005.

[10] Z. Sattari, H. Pourfaizi, Gh. Dehghan, M. Amani, A. A. MoosaviMovahedi, "Thermal inactivation and conformational lock studies on glucose oxidase," Structural Chemistry, vol. 24, pp. 1105-1110, October 2012.

[11] R.S. Koduri and M.Tien, "Oxidation of guaiacol by lignin peroxidase: role of veratryl alcohol, The Journal of Biological Chemistry," vol. 270, pp. 22254-22258, September 1995.

[12] J. Hong, W. Wang, K. Huang, W.Y. Yang, Y.X. Zhao, B.L. Xiao, Y.F. Gao, Z. Moosavi-Movahedi, S. Ahmadian, M. Bohlooli, A.A Saboury, H. Gjourchian, N. Sheibani and A.A. Moosavi-Movahedi, "A self-assembled nano-cluster complex based on cytochrome $\mathrm{c}$ and nafion: an efficient nanostructured peroxidase," Biochemical Engineering Journal, vol. 65, pp. 16-22, June 2012.

[13] T. Yang, Y.S. Zhang, X.L. Yang, F.Y. Geng, B.L. Xiao, M.M. Xu, D. Li, J. Hong, and A.A. Moosavi-Movahedi, "A novel self-assembled nano micelle as a highly efficient artificial peroxidase based on hexadecyl trimethyl ammonium bromide and cytochrome c," BioMedical Materials and Engineering, 26, pp. S73-S79, 2015.

[14] I. D. C. Vieira and O. Fatibello-Filho, "Flow injection spectrophotometric determination of hydrogen peroxide using a crude extract of zucchini (Cucurbita pepo) as a source of peroxidase, "Analyst, vol.123, pp. 1809-1812, 1998.

[15] I. H. Segel, "Enzyme kinetics," New York, pp. 926-942, 1995.

[16] A.C. Wallace, R.A. Laskowski, and J.M. Thornton, "A program to generate schematic diagrams of protein-ligand interactions," Protein Engineering, vol. 8, pp. 127-134, December 1994.

[17] B.E.P. Swoboda and V. Massey, "Purification and properties of glucose oxidase from Aspergillus niger," The Journal of Biological Chemistry, 240, pp. 2209-2215, May 1965.

[18] Q.H. Gibson, E.E.P. Swoboda, and V. Massey, "Kinetics and mechanism of action of glucose oxidase," The Journal of Biological Chemistry, vol. 239, pp. 3927-3934, November 1964.

[19] H.J. Tsuge, O. Natsuaki, and K. Ohashi, "Purification, properties, and molecular features of glucose oxidase from Aspergillus niger," Journal of Biochemistry, vol. 78, pp. 835-843, 1975.

[20] X.L. Yang, Y.S. Zhang, T. Yang, F.Y. Geng, D. Li, B.L. Xiao, J. Hong , A.A. Moosavi-Movahedi, and H. Ghourchian, "A softtemplate nanostructured peroxidase based on cytochrome $\mathrm{c}$ and 
sodium decyl sulfate and its electrochemical properties on hydroxyl fullerenes modified glassy carbon electrode," Journal of the Iranian Chemical Society, vol. 13, pp.471-479, March 2016.

[21] J. Hong, W.Y. Yang, Y.X. Zhao, B.L. Xiao, Y.F. Gao, T. Yang, H. Ghourchian, Z. Moosavi-Movahedi, N. Sheibani, J.G. Li, and A. A. Moosavi-Movahedi, "Catalase immobilized on a functionalized multiwalled carbon nanotubes-gold nanocomposite as a highly sensitive bio-sensing system for detection of hydrogen peroxide," Electrochimica Acta, vol. 89, pp. 317-325, February 2013.

[22] B.L. Xiao, J. Hong, Y.F. Gao, T. Yang, A.A. Moosavi-Movahedi, and H. Ghourchian, "Direct electron transfer of horseradish peroxidase on a functional nanocomplex modified glassy carbon electrode," BioMedical Materials and Engineering, vol. 24, pp. 1079-1084, 2014. 